\title{
Formation of the surface roughness during grinding with flap wheels after shot peening
}

\author{
Darya Starodubtseva ${ }^{1, *}$, Vinh Le Tri ${ }^{1}$, and Vladimir Koltsov ${ }^{1}$ \\ ${ }^{1}$ Irkutsk National Research Technical University, 664074 Irkutsk, Russia
}

\begin{abstract}
Shot peening is widely used in forming long panels and sheaths. Due to impact by shot on the processed surface, a specific microgeometry is formed, the characteristic feature of this microgeometry are the numerous dimples as the traces of shot impact with different diameters and depths. A presence of these dimples causes deterioration of the surface roughness parameters. Therefore, after shot peening the mandatory requirement is the implementation of surface grinding with flap wheels for partial removal of the dimples. The size of the assigned allowance for grinding depends on the quality requirements of the part surface. At the same time, the depths of the remaining dimples are determined by the part surface roughness requirements. After grinding, the new surface microgeometry is formed, as a combination of microroughness from previous types of processing and the remained dimples in result of shot peening. In this work the microgeometry formation of surface layer of the samples after shot peen forming and subsequent grinding with flap wheels was analysed. The parameters of surface roughness were measured by the method of three-dimensional optical scanning. In the measurement result, the mathematical model of the surface micro-profile formation was formulated, the analytical dependences of the position of the center plane and the arithmetic mean deviation of profile were obtained.
\end{abstract}

The surface after shot peening forming (SPF) is subject to mandatory subsequent grinding in order to partially remove the shot traces and to ensure the specified parameters of surface quality [1-4].

An operation, preceding shot peening treatment, as a rule, is machining (usually milling). As a result, on a micro-relief of the surface formed by a previous operation, the traces of shot impact are applied, and a new profile of micro-roughness is formed on this surface. The dimples as the traces of shot on the new micro-relief have different diameters and depths, which significantly exceed a level of micro-roughness from previous machining. At the same time, a distribution of these dimples on the treated surface is chaotic (random) [5,6]. An actual combination of micro-relief of these operations lets to form a new micro-relief of the part surface.

When grinding a surface with flap wheels, the value of allowance, according to [1], is determined by the average height of the micro-roughness profile (1):

\footnotetext{
*Corresponding author: d.star-irk@yandex.ru
} 


$$
a=k_{k} \cdot R z^{\text {org }}
$$

where $k_{k}$ is the surface roughness factor before and after grinding $\left(k_{k}=1 \ldots 1,1\right.$ when the height of the original micro-roughness decreases by $1-2$ times, $k_{k}=1,2 \ldots 1,25-$ by $3-4$ times); $R z^{\text {org }}$ is the height of the original micro-roughness.

It follows from (1) that the allowance value for grinding is equal to or greater than the average height of the original micro-roughness. In this case, the dimples with the depth exceeding the value of $a$, will be partially removed.

Regarding to the surface structure after shot peen forming, the allowance value $a$, characterizing the value of removal of the dimples, is determined by the depth of the dimples (Fig. 1), [7].

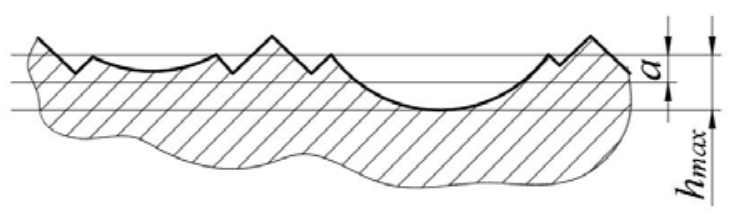

Fig. 1. Schematic representation of the part surface treated by shot peening, where $h_{\max }$ is the maximum depth of dimple; $a$ is the allowance value, which will be removed during grinding.

The maximum value of the depth of the shot dimple $h_{\max }$ on the investigating sector of the surface at grinding stage must be reduced by the allowance amount $a$ for compliance with the requirements of design documentation and tolerance of the part. In this case, a removal of all traces of shot is not necessarily and in the result after grinding a large number of shot dimples are remained.

Thus, the traces of shot peening largely determine the surface roughness of the grinding part before and after grinding.

Due to a chaotic distribution of dimples on the treated surface [1], similarly to a method for determining a height of micro-roughness within a base length $(R z)$, a height of profile micro-roughness within a base area $(S z)[6,8]$ can be determined by the following formula (2):

$$
S z=\frac{1}{5} \cdot\left(\sum_{i=1}^{5}\left|\eta_{p i}\right|+\sum_{i=1}^{5}\left|\eta_{v i}\right|\right),
$$

where $\eta_{p i}, \eta_{v i}$ - respectively 5 the highest peaks and 5 deepest valleys of the surface profile within the base area.

Analysis of the topography of the milled surfaces of the samples with subsequent shot peen forming showed the following: in general, the highest peaks of the profile are formed from previous milling process, and the deepest valleys are the deep dimples from shot peening process, herewith the bottom depths of these dimples is significantly higher than the deepest valleys from milling. Thus, the average height of the micro-roughness of the resulting surface profile is more dependent on the depth values of the largest dimples.

Figure 2 shows the scanning result with the optical profilometer «Bruker Contour GT$\mathrm{K} 1$ » of the milled surface area of the sample followed by shot peen forming. At the top of figure shows the top view of scanned surface, at the bottom - the profile of surface in the mutually perpendicular planes, passing through one of the largest dimples on the study area. 

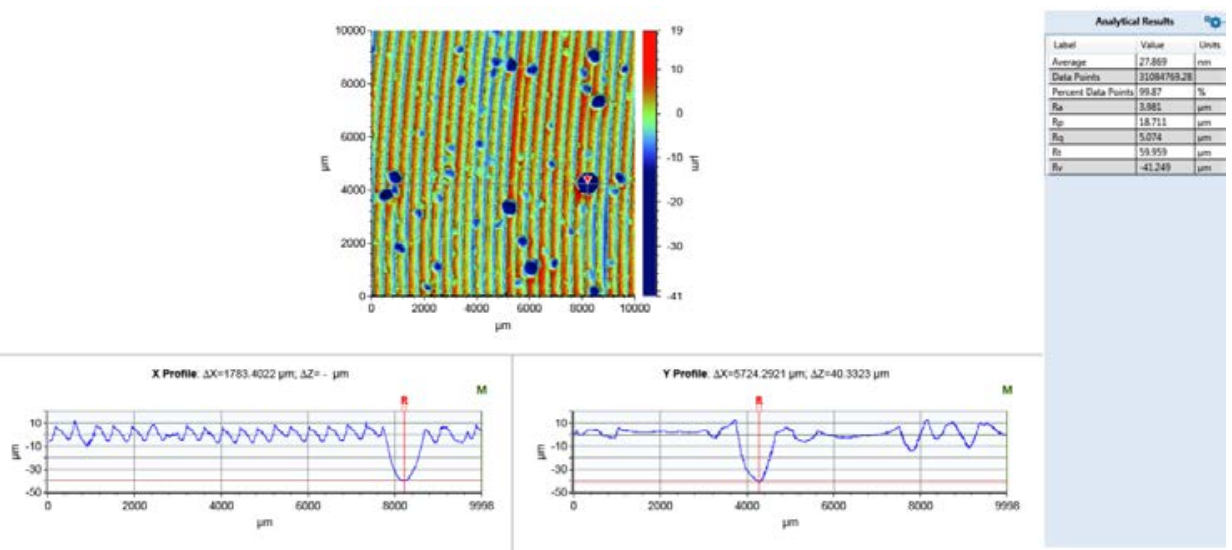

Fig. 2. The scanning result of sample surface area after shot peen forming

According to the measurement results of roughness parameters of sample, the average value $R a$ within the sampling area of the investigating sector was $3.981 \mu \mathrm{m}$, while $R p$, which characterizes the value of the profile highest peak: $18.711 \mu \mathrm{m}, R v$, the profile deepest valley: $41.249 \mu \mathrm{m}$.

In the result after grinding with flap wheels, from the processed surface of part the required metal layer was removed. Figure 3 shows the scan result for the sector area of $10 \times 10 \mathrm{~mm}$ of the cleaned surface of the sample shown in figure 2, so that the scan area for shot peen forming coincided with the scan area for grinding. This figure also shows the surface profile in mutually perpendicular planes passing through the same deepest dimple.
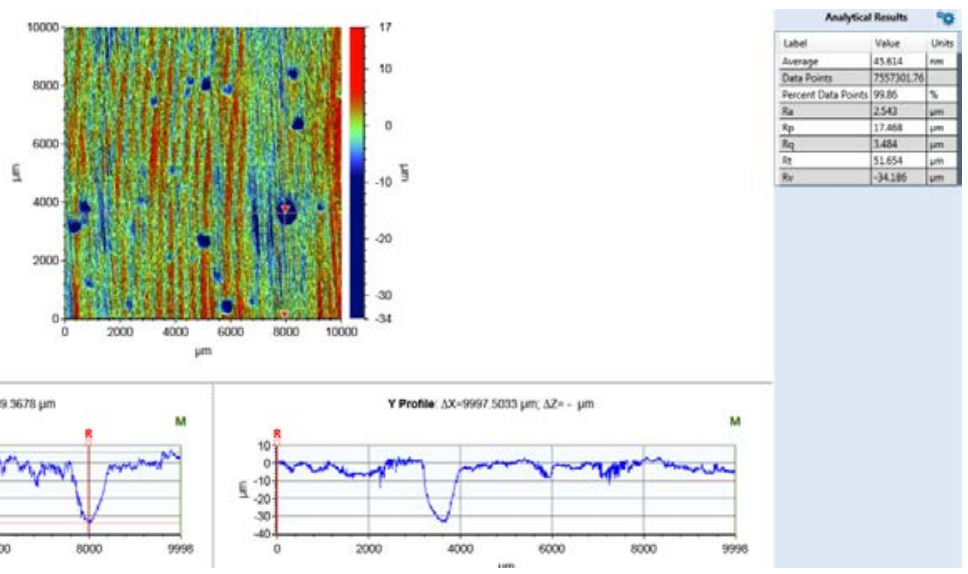

Fig 3. The scan result of surface section of the sample after shot peen forming-grinding

After grinding, the average value $R a$ within the sampling area of the investigating sector became 2,543 microns, $R p$ : 17,468 microns, $R v$ decreased to 34,186 microns.

In result of data review on the figures 2 and 3 we can conclude that even in this slight removal of the allowance by flap wheels, on machining part a new surface micro-relief is formed, as a combination of micro-roughness formed by successive stages of processing, including mechanical machining, shot peening and grinding. That is, after grinding, there are still many large dimples that are directly involved in forming the surface roughness of the machining part. It should be noted that the parameter $R a$ during grinding is not exceeded the allowable value during machining of panels and sheaths (in our case, the allowable value $R a=3,2$ microns). 
Thus, the original center plane of the surface profile formed by milling, is shifting down after shot peening [9]. In subsequent grinding the center plane also moves down when the material layer thickness within the allowance is removed. That is, the center plane of profile after grinding is below the center plane of profile after shot peening.

Figure 4 presents the graphical diagram of the location of main parameters of surface profile after milling, shot peening and grinding with flap wheels. At the same time, the basic parameters of surface roughness after grinding are determined on the basis of the location of the center plane $P_{k}$.

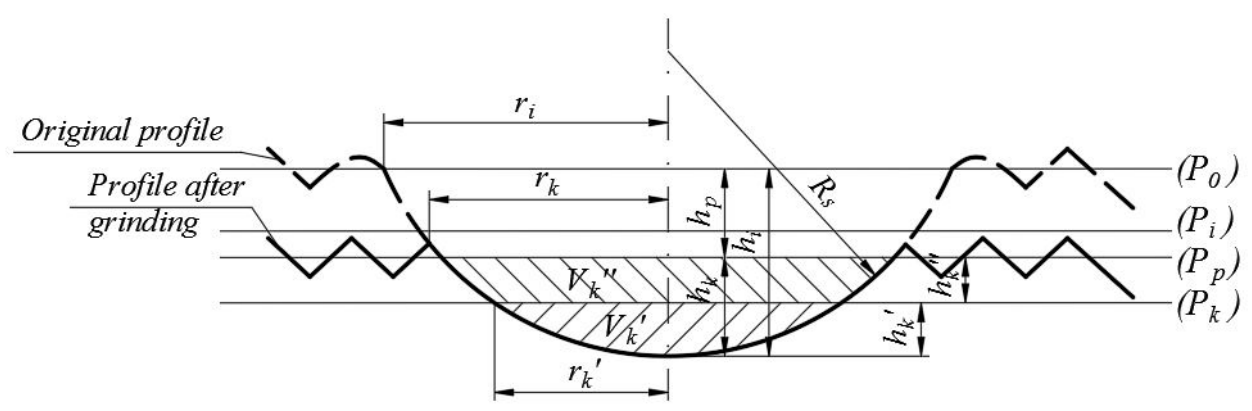

Fig. 4. The diagram of the main parameters of profile of machining part after milling, shot peening and grinding with flap wheels.

The figure 4 includes the following designations $R_{s}$ - radius of shot; $P_{0}-$ original center plane after milling; $P_{i}$ - center plane after shot peen forming; $P_{p}$ - center plane after grinding without shot peen forming; $P_{k}$ - center plane after grinding; $h_{i}$ - bottom depth of the $k$-th dimple; $h_{p}$ - allowance removed during grinding; $h_{k}$ - dimple depth after grinding; $h_{k}$ ' - bottom depth of dimple from center plane after grinding, including shot peen forming; $h_{k}$ " - distance between center plane after grinding without taking into account shot peen forming $\left(P_{p}\right)$ and center plane after grinding $\left(P_{k}\right) ; r_{i}$ - dimple radius in center plane after milling $\left(P_{0}\right) ; r_{k}$ - dimple radius in terms of center plane $P_{p} ; r_{k}{ }^{\prime}-$ dimple radius of in terms of center plane $P_{k} ; V^{\prime}{ }_{k}$ - volume of voids in dimple after grinding under center plane $P_{k}$; $V_{k}$," - volume of voids in dimple after grinding over center plane $P_{k}$.

If there are still a lot of dimples remained after grinding, then similarly to a method of determining a center plane after shot peen forming [9], the final position of center plane after grinding is determined by the following form (3):

$$
h_{k}^{\prime \prime}=\frac{\sum_{k=1}^{t} V_{k}}{F_{b}}=\frac{1}{F_{b}} \cdot \sum_{k=1}^{t} \pi \cdot h_{k}^{2} \cdot\left(R_{S}-\frac{1}{3} \cdot h_{k}\right),
$$

where $t$ - is number of dimples remained after grinding with depths exceeded a level of original micro-relief; $V_{k}$ - volume of voids of a $k$-th dimple under center plane $P_{p} ; F_{b}-$ surface area under study as a reference.

Here with,

$$
\sum_{k=1}^{t} V_{k}=\sum_{k=1}^{t} V_{k}^{\prime}+\sum_{k=1}^{t} V_{k}^{\prime \prime}
$$




$$
h_{k}=h_{i}-h_{p}
$$

So

$$
h_{k}^{\prime \prime}=\frac{1}{F_{b}} \cdot \sum_{k=1}^{t} \pi \cdot\left(h_{i}-h_{p}\right)^{2} \cdot\left(R_{S}-\frac{1}{3} \cdot\left(h_{i}-h_{p}\right)\right)
$$

Similarly to the method proposed in [9] for determining the roughness after shot peen forming, the arithmetic mean deviation of the profile within the base area after grinding is determined by the formula (7). The obtained dependence determines the value of $S a_{S P F}$ after shot peen forming without taking into account an original surface roughness.

$$
\begin{aligned}
& S a_{S P F}=\frac{2}{F_{b}} \cdot \sum_{k=1}^{t} V_{k}^{\prime}=\frac{2}{F_{b}} \cdot \sum_{k=1}^{t} \pi \cdot\left(h_{k}^{\prime}\right)^{2} \cdot\left(R_{S}-\frac{1}{3} \cdot h_{k}^{\prime}\right)= \\
& =\frac{2 \pi}{F_{b}} \cdot \sum_{k=1}^{t}\left(h_{i}-h_{p}-h_{k}^{\prime \prime}\right)^{2} \cdot\left(R_{S}-\frac{1}{3} \cdot\left(h_{i}-h_{p}-h_{k}^{\prime \prime}\right)\right)
\end{aligned}
$$

The final formula for calculating the arithmetic mean deviation of the profile within the base area after shot peen forming and grinding, taking into account the original roughness, is determined as follows (8):

$$
S a=0,5 S a_{g r i}+\frac{2 \pi}{F_{b}} \cdot \sum_{k=1}^{t}\left(h_{i}-h_{p}-h_{k}^{\prime \prime}\right)^{2} \cdot\left(R_{S}-\frac{1}{3} \cdot\left(h_{i}-h_{p}-h_{k}^{\prime \prime}\right)\right),
$$

where $S a_{g r i}$ - is the arithmetic mean deviation of the profile within the base area after grinding, excluding shot peen forming.

Formula (8) is only valid with the condition of availability of sufficient number of the remained dimples from shot peening processing. Otherwise, when the value of the allowance is close to the value of depths of the greatest dimples, the remained dimples do not have a significant impact on roughness formation of treated surface after grinding with flap wheels. That is, the formation of surface roughness during grinding with flap wheels can be considered as a process of roughness formation during traditional grinding processing.

\section{References}

1. A.E. Pashkov, Technological relationships under long sheet metal part manufacturing, Irkutsk: IrGTU Publ., p. 138 (2005), (In Russian)

2. A.E. Pashkov, A.P. Chapyshev, Interuniversity collection of scientific articles «Technological mechanics of materials», Accounting machining zone structure effect under shot peening forming, Irkutsk: IrGTU Publ., pp. 22-27 (2003) (In Russian)

3. V.P. Koltsov, D.A. Starodubtseva, M.V. Kozyreva, PROCEEDINGS of ISTU, Analysis of cuttings and part surface roughness dependences under flap wheel machining according to factorial experiment results, 1 (96), pp. 32-41 (2015) (In Russian) 
4. M.V. Bondarenko, A.P. Chapyshev, PROCEEDINGS of ISTU, On the development of a plant with numerical program control for curvilinear surfaces grinding, 10(57), pp. 24-29 (2011) (In Russian)

5. A.P. Chapyshev, Proceedings of the regional scientific and technical conference «Promising technologies of materials manufacturing and machining», (Irkutsk, 25-26 September 2004), Statistical description of surface after shot peening, pp. 42-46 (2004) (In Russian)

6. B.P. Koltsov, Vinh Le Tri, D.A. Starodubtseva, PROCEEDINGS of ISTU, To the problem of shot peening coverage degree determination, Vol 21, 11(130), pp. 45-52 (2017) (In Russian)

7. V.P. Koltsov, D.A. Starodubtseva, A.P. Chapyshev, Vestnik of Kazan State Technical University named after A.N. Tupolev, To a definition of an allowance value during grinding with flap wheels of panel and sheath surface after shot peen forming, Vol 73, 1, pp. 25-30 (2017) (In Russian)

8. A.P. Husu, Ju.R.Vitenberg, V.A. Pal'mov, Surface roughness: theoretical and probabilistic approach, Moscow: Nauka Publ., p. 344 (1975) (In Russian)

9. V.P. Koltsov, Vinh Le Tri, D.A. Starodubtseva, PROCEEDINGS of ISTU, Mathematical model of surface profile arithmetic mean deviation formation at shot peen forming, Vol. 22, 2(133), pp. 26-33 (2018) (In Russian) 